\title{
Understanding the Blind Spots of Psychosis: A Wittgensteinian and First-Person Approach
}

\author{
Zeno Van Duppen ${ }^{\mathrm{a}}$ Rob Sips ${ }^{\mathrm{b}}$

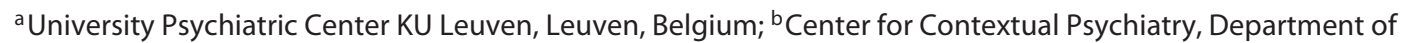 \\ Neurosciences, KU Leuven, Leuven, Belgium
}

\section{Keywords}

Phenomenology - Wittgenstein · First-person account .

Psychosis · Delusion

\begin{abstract}
Background: Experiences of psychosis are often assumed to be strange, bizarre, or incomprehensible. The aim of this article is to offer a new step towards a better understanding of how the psychotic process affects a prereflective background. Methods: We use concepts from the philosophy of Ludwig Wittgenstein to clarify the first-person perspective on psychosis of one of the authors. Results: We describe the early psychotic process as breaking down the "nest of propositions," shaking the scaffolds of our language games. Hereby, the prereflective background that forms our existential orientation in the world is fundamentally altered. We identify different aspects of this process: a dialectic of aha and anti-aha experiences, the experience of groundlessness, and blind spots. Acknowledging and exploring the depth and impact of this process on a person's world may be a first step towards resolving their isolation and suffering. Philosophy can facilitate such an exploration, while interpersonal activation may offer structure and trust in the world, helping the
\end{abstract}

\section{KARGER}

(c) 2018 S. Karger AG, Basel

E-Mail karger@karger.com

www.karger.com/psp patient to find solid ground in action and interaction. Conclusion: This article combines a philosophical approach with a first-person perspective on psychosis to illuminate aspects of psychosis that have not been described or elaborated on before. We argue that psychosis entails an experience of existential groundlessness. Our view has implications for treatment of and recovery from psychosis.

(c) 2018 S. Karger AG, Basel

"The reasonable man does not have certain doubts."

[\$220 in 1]

\section{Introduction: The Incomprehensibility of Psychosis}

Delusions, hallucinations, disorganized thought, disorganized psychomotor action, and negative symptoms are all clustered under the diagnostic concept of psychosis [2]. The presence of one or more of these psychotic symptoms can be an indication of one of the psychotic disorders, with schizophrenia considered the most severe. Although psychotic symptoms may seem strange and bizarre, research has shown that the prevalence of these

Zeno Van Duppen, MD, PhD

University Psychiatric Center KU Leuven, campus Kortenberg Leuvensesteenweg 517

BE-3070 Kortenberg (Belgium)

E-Mail Zeno.vanduppen@ upckuleuven.be 
symptoms in the general population may be remarkably high [3-6]. In one large-scale research project, up to $16 \%$ of the general population reported having experienced phenomena that clinicians would describe as psychotic [7], and a recent review reports that more than $30 \%$ of the general population claims to have had experiences that can be described as psychotic [8].

Although it has been argued that the nature of such experiences in nonclinical populations are generally different from those in psychotic clinical populations [9], the high incidence of psychotic phenomena did lead to reformulation of the "continuity hypothesis." This hypothesis states that there is continuity between normal and psychotic phenomena rather than a discrete and distinct entity of psychosis [10]. This is remarkable, firstly because of the well-known stigma concerning psychosis in the general population [11], and secondly because the conceptual history of psychosis, and particularly of schizophrenia, has emphasized the incomprehensibility and bizarreness of these phenomena [12,13]. Karl Jaspers [14] argued that delusion-like ideas, like preoccupations and real delusions, can be distinguished objectively by 3 criteria: the presence of absolute certainty, incorrigibility, and the lack of concordance with reality. He further argued that failure to understand the delusional experience is in fact the hallmark of real delusions [14]. This idea influenced current views that emphasize the need for an "explanation from the outside," in the words of Jaspers [14], instead of an empathic or phenomenological approach "from the inside", which would focus on grasping the lived experience itself. Despite the difficulty of understanding psychotic phenomena or symptoms, certain therapeutic approaches do favor a more comprehensible attitude. Indeed, movements like "open dialogue," as developed by Seikkula and Olsen [15] in Finland, particularly claim that psychosis should be treated firstly by dialogue and attempts at understanding. It thus seems that there is tension between the assumption of incomprehensibility and consequently the necessity for more explanatory approaches, e.g., neurobiology, on the one hand, and the idea that understanding is not only possible but that it may even contribute to treatment, on the other.

Phenomenological psychopathology could play a crucial role in this debate, as phenomenological authors have already shown how certain aspects of psychosis can indeed be made more comprehensible. Examples thereof are the alteration in temporal experience in the psychotic experience and schizophrenia $[16,17]$ and the change in the sense of reality [18-20]. Phenomenology also offers arguments for a different kind of understanding of these phenomena, e.g., by developing narrative or philosophical approaches to psychosis [21-23]. Nevertheless, phenomenology has only clarified certain aspects of psychosis and no one would claim to have understood psychosis in its totality.

The aim of this article is therefore to offer a new step towards a broader understanding of psychosis. The article does so by combining two perspectives: the first is the philosophy of language games as developed by Ludwig Wittgenstein; the second is the first-person perspective on psychosis of one of the authors. Wittgenstein's work has already been fruitfully used to investigate delusions [24-26]. Rhodes and Gipps [27], e.g., argued for a Wittgensteinian approach to delusions and particularly to the question how we are able to know whether someone is deluded without first making decisions about the prevalence of the belief. They employ the concept of the "background," to which we shall return further on. What we focus on here, however, is the process that precedes and outlasts the development of those delusions. In the following section, we will argue how Wittgenstein's ideas can help to disentangle this complex event. Then, in FirstPerson Perspective on Psychosis, we offer insights from the experience of psychosis of the second author and show how Wittgenstein's ideas can make these more understandable. Lastly, in Conclusion: Recovery and Covering the Blind Spots, it will become clear why these insights can be relevant for therapy and recovery.

\section{A Wittgensteinian Approach}

In this section, we present some of the key notions in the work of Wittgenstein, which will help to elucidate a part of the psychotic experience. We discuss in particular language games, forms of life, and the background, and we pay special attention to the notions of doubt and certainty.

Wittgenstein introduced the concept of language games to address problems concerning the meaning of words, i.e., their unfixedness, the multiplicity of uses, and their being relative to an activity [28]. This allowed for a flexible and action-oriented perspective on language and words. Although he did not explicitly define the concept of language game, we find preliminary indications for the concept already in the Tractatus Logico-Philosophicus. There, he considered language to be a structure of signs, names, and propositions [ $\$ 4.22$ in 29]. Propositions are built of more elementary propositions, which in turn are constituted by names and signs that cannot be further 
"taken to pieces by definitions" [\$4.221 in 29]. Those most elementary parts only become meaningful in their use and application [ $\$ 3.262$ in 29]. It is this practical and action-oriented turn that he would further elaborate in his later works.

In On Certainty [1], e.g., Wittgenstein described how language games emerge from action. A language game is a practically learned interconnection of propositions that are coherently bound together through its use and application. A language game is purpose relative and could be considered as the set of words and phrases determined by and determining adequate ways of dealing with a particular activity. If one were aiming to justify the propositions within a language game, through empirical testing, e.g., justification of these propositions ultimately would come to an end. Even at the foundation of well-founded belief lies belief that is not founded [ $\$ 253$ in 1]. Logically, Wittgenstein expresses it in the following way: "If the true is what is grounded, then the ground is not true, not yet false" [\$205 in 1]. An attempt to justify or reduce once firmly held propositions, even in an intersubjective context, leads to the discovery of ungrounded belief. Our judgments, e.g., about activities, are not based on a single foundational proposition but rather on "a nest of propositions" [ $\$ 225$ in 1]. It is its interconnection from which the language game derives its structure rather than from a solid ground. Using the metaphor of a house, Wittgenstein indicated that the "foundation walls are carried by the whole house" $[\$ 248,1]$, thereby inverting our conventional understanding of (architectural) foundations [30]. What holds the house together is the interconnection and our practice: "The only end one could discover is not an ungrounded presupposition: it is an ungrounded way of acting" $[\$ 110,1]$. One could interpret the concept of common sense of the German psychiatrist Blankenburg [31] in very much the same way, as the prereflective and prepredicative self-evident apprehension of the everyday world that arises from interaction with others. Blankenburg [31] pointed out that it is exactly this self-evident common sense which breaks down in schizophrenia.

We learn the rules of the language game "purely practically, without learning any explicit rules" [ $\$ 95$ in 1]. It is, however, against a particular background that we are able to learn these rules and meanings. This is the background of what Wittgenstein called our forms of life or our world picture, i.e., our habits of doing things together in common environments, which make meaning and learning of meaning possible [32]. The ungrounded way of acting to which Wittgenstein refers does offer a certain ground. However, this ground is not the propositional

The Blind Spots of Psychosis certainty within a particular language game but rather a certainty in action [33].

Language games are characterized by the exclusion of particular doubts. According to Wittgenstein, our attempts to enquire, e.g., in scientific research, are set up in such a way that some propositions are exempted from doubt, if they were ever formulated in the first place. "They lie apart from the route travelled by enquiry" [ $\$ 88$ in 1]. We can certainly question the correspondence to reality or the correctness of specific propositions, yet there are some which we cannot even think of questioning because they are like "hinges" on which the whole language game turns. Thus, it belongs to the logic of our investigations "that certain things are in deed not doubted" $[\$ 342,1]$. This is not only the case for scientific research but also for every kind of enquiry, idea, or belief about the world. Even our concept of rationality itself depends on the correct exclusion of certain doubts [ $\$ 220$, 1]. This is not to say that doubt is not possible within the language game. However, the doubt within the language game is doubt about a particular knowledge, e.g., a proposition, while the doubt which is excluded from the language game concerns those basic certainties that function as conditions for the language game itself. They "enable sense" instead of themselves having sense [p. 134 in 34].

These certainties in action build the background or bedrock that allows for doubt to be possible in the first place. In other words, "propositions evincing knowledge claims belong to the language game, whereas certainty grounds the language game and is a condition of its possibility" [p. 7 in 35]. A language game and the meanings it carries emerge from a practical reality or community in which activities take place. The basic certainties are instinctively and immediately relied on. They constitute a certain trust in the world, in the reality of things [32]. We do not get our picture of the world by testing every propositional statement about the world, nor do we have to satisfy ourselves about the correctness of our beliefs. "No: it is the inherited background against which I distinguish between true and false" [ $\$ 94$ in 1]. In their work on delusions, Rhodes and Gipps [27] argue that it is this very prepredicative and prereflective background that allows us to grasp a delusional belief as delusional.

Yet it is possible that forms of life or world pictures, and therefore the language games that emerge from them, change. Thus, language games are not universal or invariable. Wittgenstein compares these changes to a changing riverbed: some elements are part of the river, of the ever changing and instable stream, while others are firmly sedimented into the riverbed. Yet, even though there seems 
to be a strict distinction between the stream and the riverbed, some sediments may shift into the stream, while elements of the stream become part of the riverbed. This means that certain beliefs we hold for undeniable certainties may one day change and become obsolete or lose their status as certainties. Certainly, there are empirical propositional truths we hold, and uncertainties and doubts we may have, but the difference between the two, Wittgenstein argues, is not that strong [ $\$ 97$ in 1]. Our picture of the world can change, and with it the meanings of the propositions and names of language games change [ $\$ 65$ in 1]. A clear example thereof in the history of science is the discovery of heliocentrism, or more recently the discovery of genetic material $[36,37]$.

Thus, Wittgenstein claims that a language game is a practically learned interconnection of propositions coherently bound together through their use and application. They are not based on any final foundational justification. They rather emerge from a background that reflects forms of life or a world picture. Although the lack of a foundational ground may indicate groundlessness, there are certainties in action and shared forms of life. The exclusion of the formulation of, and doubt about particular propositions enables a language game and the meanings it holds. These propositions function "like hinges" on which the language game turns. The language game thus emerges as a given within a broader background of forms of life, which themselves may change. Wittgenstein's philosophy itself points to the "hinge propositions," the undoubted certainties and the inherited background and forms of life. Philosophy practice and writing itself include a multitude of language games. Yet, they help us indicate the limitations, the blind spots, and the uncertainties that are seldom acknowledged. One could even feel unconformable reading about the groundlessness of one's belief and start to doubt the "rules of the game." Indeed, as Wittgenstein acknowledges himself: "The difficulty is to realize the groundlessness of our believing" [ $\$ 166$ in 1$]$. We will see now how this will help us to understand a vital aspect of psychosis.

\section{First-Person Perspective on Psychosis}

In this section, we offer insight into psychosis as based on the experience and descriptions of the second author (hereafter R.S.). A first-person perspective is, however, not entirely unproblematic. The language one uses to describe these experiences might sound banal or seem incomprehensible. Nevertheless, such descriptions may be attempts to express the breath-taking disorientation and the terrifying confusion psychosis often implies. Philosophy may play an important role here. It can help to examine aspects of reality that usually fall outside of our common-sense understanding and it can help to translate and facilitate the expression of seemingly incommunicable experiences. By applying Wittgenstein's philosophy in particular, we hope to illustrate aspects of the psychotic process from the earliest predelusional alterations past the well-developed delusions. A second problem related to the first-person account is whether the results of our phenomenological examination will be generalizable to other people's psychotic experiences. Although we find indications thereof in our clinical experience, the aim here is to firstly clarify this process based on one account, and only secondarily will we search for generalizability and extrapolation, in much the same way as phenomenological analyses work. To do so, we rely on the notes that R.S. took during psychotic episodes, and we will show how Wittgenstein's vocabulary can be of help to increase our understanding of psychosis. We will firstly encounter the delusional mood, followed by the dialectic of aha and anti-aha experiences, and lastly we will describe blind spots. This will enable us to clarify, in Conclusion: Recovery and Covering the Blind Spots, what the role of philosophy could be in the process of recovery.

\section{Delusional Mood}

Delusional mood or delusional atmosphere is the state preceding the development of delusions, in which patients describe experiential changes to the environment, and in which it seems that, somehow, the world acquires new meaning $[19,38]$. Jaspers [14] first coined the term to emphasize the uncanny and puzzling feeling that something indeterminate is happening. We will illustrate here that this predelusional state concerns more than an altered perception and that, indeed, the delusional mood already illustrates the disconnection from a common language game and from the background that Wittgenstein described.

This predelusional state often has a revelatory character, as Conrad [19] already noticed and defined as "apophany.” During the onset of the first psychosis, R.S. described it in the following way:

"... it is as if I am looking at reality with other eyes, it almost seems as if I am awakening." (R.S.)

"It is a super weird feeling. From one day to the next, even from one moment to another, I can think and reason again clearly... It sort of feels as if I have found a key to something that has been locked for a long while... Because my head is clear, and my process
Van Duppen/Sips 
of reasoning seems to function better than ever before, I seem to perceive much more and seem to be capable of much, much more." (R.S.)

To him, it felt as if the world showed itself anew. Although it clearly involved an altered experience, it did not concern or follow from a perceptual change, e.g., a hallucination. There was an increasing subjective tension, accompanied by continuously recurring "insights." These were new ways of looking at things, of understanding problems and situations one has to deal with, that usually seem selfevident. The recurrent insights during the first delusional mood mostly concerned his personal and relational life, while afterwards the new perspectives included more existential and transcendental matters. One's world picture that enables one to meaningfully experience the worlds, others, and one's self was fundamentally altered. It felt like he could suddenly see things from completely new perspectives. These new perspectives weakened in R.S. the bias through which we consider our own perception, thoughts, and beliefs as objective [p. 43 in 40]. The rigidity of the language game that normally pervades our lives became questionable [p. 59 in 40]. While the new perspectives on the world were overwhelming and frightening, there were no easy answers to be found. Although the beginning of the delusional mood mostly entailed questions and perspectives on his personal life, later on everything became doubtful and everything seemed different.

"I suddenly question everything, and look for confirmation of the multitude of insights that come to mind, just because I literally question everything... The question of The One, the all-encompassing... I can't explain what this feels like. My whole world is upside down.” (R.S.)

He felt urged to question everything, from personal motivations to philosophical themes like the principle of unity and temporality. These themes are often found in first-person accounts on psychosis, but they also play an important role in mystic philosophy [41]. In the following quote, one recognizes the need to question what once seemed self-evident.

"The entire world runs on a time that people have invented. They did this by seeing a certain logic in things (day, night, morning, evening, midday $\rightarrow$ half of a day). There is a recurrent logic in the way we reason about time... To really realize what time is, you arrive at the eternal questions, namely why does it become dark and light... In this you can go further again. Why does the sun move in front of the moon... And then (I think) you arrive at gravity. Then you can ask, why is there gravity, and then you can try to explain gravity... Like this, you can keep going on until you're not able to grasp things anymore, or someone else sees the logical connections and you are able to understand them. Pi in mathematics? How far can one contain pi, or the absolute truth?" (R.S.)

The Blind Spots of Psychosis
In striking similarity to these descriptions of the onset of the first psychotic episode, Wittgenstein describes the stream of thoughts of "the man who is philosophically puzzled."

\footnotetext{
"The man who is philosophically puzzled sees a law in the way a word is used, and, trying to apply this law consistently, comes up against cases where it leads to paradoxical results. Very often the way the discussion of such a puzzle runs is this: First the question is asked, 'What is time?'. This question makes it appear that what we want is a definition. We mistakenly think that a definition is what will remove the trouble (as in certain states of indigestion we feel a kind of hunger, which cannot be removed by eating). The question is then answered by a wrong definition; say: 'Time is the motion of the celestial bodies.' The next step is to see that this definition is unsatisfactory. But this only means that we don't use the word 'time' synonymously with 'motion of the celestial bodies.' However in saying that we must replace it by a different one, the correct one. If we are ready to give any explanation, in most cases we aren't. Many words in this sense don't have strict meaning." [p. 27 in 40$]$
}

Both the psychotic questions in the first quote and the philosophical reflections of Wittgenstein's example reach the limitations of our language games. They stumble upon the background beliefs that seem valid because of their application rather than because of a certain ground or foundation. The concept of time is indeed a clear example of such a background notion. Everyone uses it daily, while at a closer glance few are able to give a satisfying final answer to the question on the nature of time. And for R.S., the common-sense notion of time did not suffice and kept urging further questioning without offering solid ground for answers.

However, the example of time does not suffice to grasp the whole puzzling experience of the delusional mood and of the onset of psychosis. This equally implies losing grip of "the right manner" of seeing things. The language games and the background beliefs constitute social reality as well, and they structure our perception of and interaction with others. The habitual ways we have learned from others and which we have incorporated into our own most personal ideas, convictions, and behaviors may suddenly lose their self-evidence [42]. A simple thing like cooking dinner thus becomes an impossible task, irrelevant in light of a changing reality. We consider it crucial that one aspect that determines the devastating experience of psychosis is this fundamental alteration of a framework of meaning and significance, which Wittgenstein called the background. To clarify how the pre-delusional state of confusion, questioning, and insights further evolves into a psychotic breakdown, we introduce what R.S. called the dialectic of the aha and anti-aha experiences. 
The Dialectic of Aha and Anti-Aha Experiences

What are the recurrent insights we claim are an essential part of the early psychotic experience? To understand this, Sips [43] revisited the notion of the aha experience and introduced the anti-aha experience to denote the psychotic process as dialectical. The former involves a sudden insight, understanding, or realization of a previously incomprehensible or even undetected problem. ${ }^{1}$ In case descriptions of the predelusional state one can find many examples of the sudden and unexpected aha experience $[38,39,41,44-46]$. The aha experience can have both a perceptive and a cognitive dimension. An example of the former would be the shift we experience in the famous "duck-rabbit" image, where one first and only perceives either a duck or a rabbit, and suddenly one sees the other one [47]. A cognitive example would be solving a riddle after a phase of incubation, where one suddenly understands the clue. Another example would be a game of chess, where one can suddenly "see" a possible move or a strategy. This insight is not rationally devised or argued for, but it presents itself to the player. Suddenly the game is seen from a new perspective. Without one piece on the board being moved, the game acquires a new meaning for the player. The aha experience in psychosis equally involves a sudden feeling of clarity and, as the first quote in this article illustrates, R.S. experienced it as an "awakening."

There is, however, also an antithetical variation of the aha experience. Sips [43] defined this anti-aha experience as an experience of sudden insight that does not fit within one's framework, convictions, or worldview. Like the aha experience, it involves a clear and sudden insight, but instead of contributing to one's personal worldview it breaks it down and disconfirms the previous standpoint or convictions. To return to the game of chess, one could have a particular move or strategy in mind that would clearly lead to victory. The feeling one has could then be one of confidence, belief, and certainty about the outcome of the game. Then, suddenly, the opponent makes a move and, unexpectedly, one finds oneself in a checkmate position. In a brief moment, one's perspective on the game is completely changed. The confidence and certainty about the victory are replaced by feelings of disbelief, shock, and defeat. In very similar ways, the anti-aha

\footnotetext{
1 The term "realization" is used to denote a subjective experience of clarity and insight, without any reference to an objective or external truth.

2 See Sass [p. 24 in 24] where he writes that "it has not in fact been sufficiently noted how often schizophrenic delusions involve not belief in the unreal but disbelief in something that most people take to be true."
}

experience can suddenly devastate earlier beliefs, convictions and a particular perspective that one held to be undoubtedly true. An example thereof is the sudden realization R.S. had that his entire life before the psychotic episode was just as unreal as the experience of psychosis itself. R.S. equally experienced how certain insights could undermine the meaning of things, words, and concepts in such a way that even the foundation of his moral views seemed to become groundless.

We propose to think of the onset of a psychotic episode as involving a dialectal process of aha and anti-aha experiences that dismantle the "nest of propositions" [ $\$ 225$ in 1] that forms the background of our existential orientation [48] and motivates our actions, perceptions, and beliefs. The anti-aha experiences are "insights" that cause shifts in the character of language games and urge reinterpretations of reality or world pictures, possibly resulting from an invalidation of previously held and mostly prereflective convictions or beliefs. Even though a world picture, as we have seen, is an interpersonally constituted framework, it does determine one's most subjective or personal relation with the world [p. 306 in 27]. Therefore, an alteration in this framework, as we suggest happens in psychosis, equally leads to a drastic change in the totality of one's personal experience and view of the world, as the example of the undermining of the meaning of things, words, and concepts illustrated earlier.

We describe the dialectic between the aha and the anti-aha experience as a process rather than a single event. It is the repeating and recurring character of these oppositional and undermining insights that leads to a feeling of groundlessness. If every new insight shows a different perspective, which perspective is the right one? If a new insight is invalidated by a following one, what is there to be certain about? In contrast to the lack of multiperspectivity within the delusion [49], the predelusional state may thus include an overwhelming multiperspectivity [50]. The sequence of questions and answers ultimately leads, as Wittgenstein already indicated, to a lack of foundation. This, in turn, induces the frightening experience of groundlessness, and a "certain uncertainty" [p. 45 in $51 .^{2}$ Within the natural attitude of everyday life, we seldom arrive at this conclusion. It even seems that we have a certain resistance against this perspective on reality. Yet, where Wittgenstein describes that the difficulty "is to realize the groundlessness of our believing" [ $\$ 166$ in 1], the early psychotic process seems to show the difficulty to deal with this groundlessness without finding any appropriate answer. 


\section{Blind Spots}

One way to understand the realization of groundlessness is to focus on "blind spots." Blind spots are those elements that determine a language game and that we are (or can be) blind to in our everyday interactions. To reiterate the game of chess, a blind spot could be a possible move on the board that one just did not see. Yet, our blindness to the craftsmanship with which the pieces and the board are created, while we only see the game unfold itself, even more so indicates what we describe with the concept of blind spot. Similarly, in order to properly function within a language game we must (at least partially or temporally) be blind to a lot of its possibilities. To adequately drive a car in traffic, we immediately need to grasp the signalization on the street instead of contemplating the color of a particular signpost, questioning the material of the car in front, or focusing on the license plates of the cars passing by. This exclusion is helpful and necessary, and insight into these other possibilities is not necessarily problematic. However, the blind spots may also include the "hinge propositions" [ $\$ 342$ in 1$]$ on which a whole language game turns and which are excluded from doubt, like the self-referential spiral that is inherent in human self-consciousness [52].

As we now know, these blind spots are seldom perceived or acknowledged in our self-evident and commonsense relation to the world. In fact, it is impossible to remain within a particular language game and nevertheless perceive and describe these blind spots. Furthermore, approaching a blind spot, or suddenly becoming aware of one, leads to resistance or even anxiety, urging one to ignore or forget it. William Byers [52] described this as "shocking and disturbing." In psychosis, the dialectical process of aha and anti-aha experiences and the groundlessness resulting therefrom can lead to a realization of blind spots. This is an experience which is described to be disorienting and it implies a particular loosening of the ties with others and with the everyday world. What used to give direction to one's life can get lost in the psychotic process. In the earlier example, the groundlessness of words, concepts, and morality which R.S. experienced urged an existential crisis, devaluating his personal convictions and paralyzing him to make concrete decisions in everyday life.

The experience of blind spots is thus not some mystical insight into the absolute truth. It rather concerns essential structures of the language game, the world picture, and the background. The psychotic process entails a particular step out of the closed language game. The blind spots show how a personal familiarity one has acquired with the world may be based on only one perspective, but that this particular perspective equally excludes other ways of seeing, living, being, and thinking. The being-at-home in the world, or the life form, suddenly changes through this realization. If this changes, the whole meaningful and personal life narrative one has constructed becomes questionable. Every process of growth into adulthood, and certainly further on, includes these changes as well, but it firstly does so in a less intense and less devastating way, and secondly it does so while offering a new framework that is shared with others. In psychosis, however, the realization of certain blind spots through the experience of groundlessness leaves a person devastated and alone to deal with it.

One historical nonpathological example that may help to grasp this idea of the blind spot, and the impact its realization may have, is found in the famous letter Bertrand Russel [53] wrote to Gottlob Frege on his discovery of the paradox which would show that the axioms Frege was using to formalize logic were, in fact, inconsistent $[53,54]$. The whole system Frege had constructed as a foundation for mathematical and thus scientific knowledge collapsed. In a time when many considered logic and mathematics to be the only scientific way to knowledge and truth, the discovery of the blind spot in Frege's work led to pure consternation and Frege long after attempted in vain to undo the damage to his system of certainty [55]. Another example is solipsism, or the idea that only one's own mind or self is real, while the reality of others is questioned. This idea is reported to be often present in psychotic experiences $[24,56]$. It is difficult for anyone to defy solipsism purely on the basis of rational arguments instead of using one's "basic trust" that, in the end, the world and the others do exist independently. It becomes that much harder when this "insight" is accompanied by actual feelings of disconnection from others and the once undoubtable trust becomes fragile [57]. Our self-evident world picture, however, mostly ignores such ideas. These are insights which we would rather not have and which we may even deliberately attempt to forget.

The uncovering of the blind spots, urged by the ahaand anti-aha dialectic and driven by the tension of the delusional mood, may then give rise to the formation of delusional certainties. In a way, delusions may be ways of idiosyncratically making sense of the chaos that this predelusional state is causing [58-60]. In this process, the alterations that shake the scaffolds of the language games and world picture serve as a matrix for the crystallization of delusional certainties - certainties that are, however, intrinsically unshareable. 


\section{Conclusion: Recovery and Covering the Blind Spots}

By combining Wittgenstein's ideas with a first-person account of psychosis, it has become clear that the early psychotic process can break the "nest of propositions" [ $\$ 225$ in 1] that forms the background of our existential orientation [48] and motivates our actions, perceptions, and beliefs. We argued that the dialectic of aha and antiaha experiences transgresses the boundaries of language games, imposing a multiplicity of perspectives on reality which leads to the experience of groundlessness and blind spots. A consequence of this process is that it is an isolating experience, where one is left alone to face these devastating insights. While the doubts and uncertainties of other people generally remain within the commonsensical language game, the early psychotic uncertainty can question and undermine this commonsensical language game and the world picture in which it is embedded itself.

We consider the delusional mood, the dialectic of ahaand anti-aha experiences, and the uncovering of blind spots to be intertwined moments of the predelusional state. This means that we cannot distinguish a clear chronology or etiology and, consequentially, we find no arguments to support any of the prominent 2-step models of delusion formation that either claim that perceptual disturbances lead to cognitive disturbances or the other way around. In our account the perceptual, the cognitive, the prereflective, and the reflective aspects of psychosis are tightly interwoven. What all of these alterations together entail is a radical reorientation in the lived world. We will now focus on possible consequences of this account for recovery.

The treatment of psychosis mainly focuses on the acute positive symptoms, like hallucinations and delusions [61], and thereby mostly overlooks possible preceding psychotic alterations that may outlast the positive symptoms. The experience of groundlessness and of blind spots is in our view, however, an essential aspect of the early psychotic process, which can remain present long after the delusions have dissolved. One reason why this may be the case is that these insights are often so idiosyn- cratic that they are experienced as unsharable, or that one fears these ideas to be incomprehensible, an attitude sometimes reflected in the lack of understanding by others. Therefore, from a therapeutic standpoint, acknowledging the blind spots and exploring the depth of the impact of the anti-aha experiences can be a first step to resolving the isolation. If recovery indeed implies social cover [62], "covering" the blind spots would be appropriate. Attempts to face and understand these insights can decrease their devastating impact [63]. Philosophy facilitates such an exploration, as it can offer a language for those experiences, thoughts, and insights.

Although philosophy may be helpful to some, it is plausible that it would not benefit others. Moreover, the shared explorations we assume to be helpful only explicitly target the propositional and reflective aspects of psychosis, while we consider the prereflective and nonpropositional to play a significant role as well. Recovery, in our view, does not primarily imply "regaining insight" or "reality testing." We certainly agree with Rhodes and Gipps [p. 308 in 27] and with Ghaemi [64] who have argued that a Wittgensteinian understanding of psychosis indicates that only focusing on reflective or cognitive therapy is not expected to change much to the background alterations, nor will it enable the reestablishment of one's habitual ways of being. It seems crucial to renew the possibility of sharing the world with others and connecting to these others in a prereflective manner as well. They can offer structure and trust in the world, helping the patient to find solid ground in interpersonal relations. If we follow Wittgenstein's idea that the ground of our language games is our ungrounded way of acting, and if we consider the psychotic process able to break the "nest of propositions" that forms language games, then therapy for psychosis should focus in particular on shared, interpersonal activities - activities which Wittgenstein considers ungrounded but which themselves, through their interpersonal character, may rebuild basic trust in others, in the world, and in oneself through certainty in action and thereby offer at least some ground to recover on.

\section{References}

1 Wittgenstein L: On Certainty. Oxford, Blackwell, 1969.

2 American Psychiatric Association: Diagnostic and Statistical Manual of Mental Disorders, ed 5. Washington, American Psychiatric Association, 2013.

3 van Os J, Hanssen M, Bijl RV, Ravelli A: Strauss (1969) revisited: a psychosis continuum in the general population? Schizophr Res 2000;45:11-20.
4 Johns LC, van Os J: The continuity of psychotic experiences in the general population. Clin Psychol Rev 2001;21:1125-1141.

5 Rössler W, Riecher-Rössler A, Angst J, Murray R, Gamma A, Eich D, van Os J, Gross VA: Psychotic experiences in the general population: a twenty-year prospective community study. Schizophr Res 2007;92:1-14. 
6 Yung AR, Nelson B, Baker K, Buckby JA, Baksheev G, Cosgrave EM: Psychotic-like experiences in a community sample of adolescents: implications for the continuum model of psychosis and prediction of schizophrenia. Aust NZ J Psychiatry 2009;43:118-128.

7 van Nierop M, van Os J, Gunther N, MyinGermeys I, de Graaf R, ten Have M, van Dorsselaer S, Bak M, van Winkel R: Phenotypically continuous with clinical psychosis, siscontinuous in need for care: evidence for an extended psychosis phenotype. Schizophr Bull 2012;38:231-238.

8 Nuevo R, Chatterji S, Verdes E, Naidoo N, Arango C, Ayuso-Mateos JL: The continuum of psychotic symptoms in the general population: a cross-national study. Schizophr Bull 2012;38:475-485.

9 Stanghellini G, Langer ÁI, Ambrosini A, Cangas AJ: Quality of hallucinatory experiences: differences between a clinical and a non-clinical sample. World Psychiatry 2012;11:110-113.

10 Strauss JS: Hallucinations and delusions as points on continua function: rating scale evidence. Arch Gen Psychiatry 1969;21:581586.

11 Penn DL, Kommana S, Mansfield M, Link BG: Dispelling the stigma of schizophrenia. 2. The impact of information on dangerousness. Schizophr Bull 1999;25:437-446.

12 Kraepelin E: Psychiatrie: Ein Lehrbuch für Studierende und Ärzte, 7. Vielfach umgearbeitete Auflage. Leipzig, Barth, 1904, vol 2.

13 Gilman SL: Why is schizophrenia "bizarre": an historical essay in the vocabulary of psychiatry. J Hist Behav Sci 1983;19:127-135.

14 Jaspers K: Allgemeine Psychopathologie, ed 4. Berlin, Springer, 1948.

15 Seikkula J, Olson ME: The open dialogue approach to acute psychosis: its poetics and $\mathrm{mi}-$ cropolitics. Fam Process 2003;42:403-418.

16 Fuchs T: The temporal structure of intentionality and its disturbance in schizophrenia. Psychopathology 2007;40:229-235.

17 Fuchs T, Van Duppen Z: Time and events: on the phenomenology of temporal experience in schizophrenia (ancillary article to EAWE Domain 2). Psychopathology 2017;50:68-74.

18 Schwartz M, Wiggins O, Naudin J, Spitzer M: Rebuilding reality: a phenomenology of aspects of chronic schizophrenia. Phenomenol Cogn Sci 2005;4:91-115.

19 Ratcliffe M: Delusional atmosphere and the sense of unreality; in Stanghellini G, Fuchs T (eds): One Century of Karl Jaspers' General Psychopathology. Oxford, Oxford University Press, 2013, pp 229-244.

20 Van Duppen Z: The phenomenology of hypoand hyperreality in psychopathology. Phenomenol Cogn Sci 2016;15:423-441.

21 Ratcliffe M: Phenomenology as a form of empathy. Inquiry 2012;55:473-495.

22 Stanghellini G: The ethics of incomprehensibility; in Stanghellini G, Fuchs T (eds): One Century of Karl Jaspers' General Psychopathology. Oxford, Oxford University Press, 2013, pp 166-181.
23 Henriksen MG: On incomprehensibility in schizophrenia. Phenomenol Cogn Sci 2013; 12:105-129.

24 Sass LA: The Paradoxes of Delusion: Wittgenstein, Schreber, and the Schizophrenic Mind. New York, Cornell University Press, 1994.

25 Varga S: Depersonalization and the sense of realness. Philos Psychiatr Psychol 2012;19: 103-113.

26 Broome M: Reality, realness, and the natural attitude. Philos Psychiatr Psychol 2012;19: 115-118.

27 Rhodes J, Gipps GT: Delusions, certainty, and the background. Philos Psychiatr Psychol 2008; 14:295-310

28 Biletzki A, Matar A: Ludwig Wittgenstein. Stanford, Metaphysics Research Lab, Stanford University, 2008.

29 Wittgenstein L: Tractatus Logico-Philosophicus. London, Kegan Paul, Trench, Trubner, 1922.

30 Rhees R: Wittgenstein's On Certainty: There - Like Our Life. Wiley, 2008.

31 Blankenburg W: Ansätze zu einer Psychopathologie des "Common Sense". Confin Psychiatr 1969;12:144-163.

32 Pihlström S: A new look at Wittgenstein and pragmatism. Eur J Pragmat Am Philos 2012, p 4

33 Moyal-Sharrock D: Wittgenstein's razor: the cutting edge of enactivism. Am Philos Q 2013; 50:263-279.

34 Moyal-Sharrock D: Logic in action: Wittgenstein's logical pragmatism and the impotence of scepticism. Philos Invest 2003;26:125-148.

35 Stroll A: Moore and Wittgenstein on Certainty. Oxford, Oxford University Press, 1994.

36 Kuhn TS: The Structure of Scientific Revolutions. Chicago, The University of Chicago Press, 1962

37 Feyerabend P: Against Method. London, Verso, 1993.

38 Fuchs T: Delusional mood and delusional perception: a phenomenological analysis. Psychopathology 2005;38:133-139.

39 Conrad K: Die beginnende Schizophrenie: Versuch einer Gestaltanalyse des Wahns. Stuttgart, Thieme, 1958.

40 Wittgenstein L: The Blue and Brown Books: Preliminary Studies for the "Philosophical Investigations." New York, Harper Perennial, 1960.

41 Kusters W: Filosofie van de waanzin. Rotterdam, Lemniscaat, 2014.

42 Blankenburg W: Der Verlust der Natürlichen Selbstverständlichkeit: Ein Beitrag zur Psychopathologie symptomarmer Schizophrenien. Stuttgart, Enkel, 1971.

43 Sips R: Psychosis as a dialectic of Aha- and Anti-Aha-experiences. Schizophr Bull 2018, DOI: $10.1093 /$ schbul/sby072.

44 Mishara AL: Klaus Conrad (1905-1961): delusional mood, psychosis, and beginning schizophrenia. Schizophr Bull 2010;36:9-13.

45 Kusters W: Philosophy and madness: radical turns in the natural attitude to life. Philos Psychiatr Psychol 2016;23:129-146.
46 Parnas J, Henriksen MG: Mysticism and schizophrenia: a phenomenological exploration of the structure of consciousness in the schizophrenia spectrum disorders. Conscious Cogn 2016;43:75-88.

47 Wittgenstein L: Philosophical Investigations. Oxford, Blackwell, 1953.

48 Ratcliffe M: Feelings of Being: Phenomenology, Psychiatry and the Sense of Reality. Oxford, Oxford University Press, 2008.

49 Blankenburg W: Wahn und Perspektivität: Störungen im Realitätsbezug des Menschen und ihre Therapie. Stuttgart, Enke, 1991.

50 Schwartz MA, Wiggins OP, Spitzer M: Psychotic experience and disordered thinking: a reappraisal from new perspectives. J Nerv Ment Dis 1997; 185:176-187.

51 Müller-Suur H: Das Gewissheitserlebnis beim schizophrenen und beim paranoischen Wahn. Fortschr Neurol Psychiatr 1950;18: 44-51.

52 Byers W: The Blind Spot: Science and the Crisis of Uncertainty. Princeton, Princeton University Press, 2011.

53 Russell B: Letter to Frege; in van Heijenoort J (ed): From Frege to Gödel. Cambridge, Harvard University Press, 1967, pp 124-125.

54 Bell D: Russell's Correspondence with Frege. Oxford, Blackwell, 1980.

55 Dummett M: Frege: Philosophy of Language. Cambridge, Harvard University Press, 1981.

56 Parnas J, Sass LA: Self, solipsism, and schizophrenic delusions. Philos Psychiatr Psychol 2001;8:101-120.

57 Van Duppen Z: The intersubjective dimension of schizophrenia. Philos Psychiatr Psychol, in press.

58 Gipps RG, Rhodes J: The background theory of delusion and existential phenomenology. Philos Psychiatr Psychol 2008;15:321-326.

59 Stanghellini G: Schizophrenic delusions, embodiment, and the background. Philos Psychiatr Psychol 2008;15:311-314.

60 Fuchs T: Phenomenology and psychopathology; in Gallagher S, Schmicking D (eds): Handbook of Phenomenology and the Cognitive Sciences. Dordrecht, Springer, 2010, pp 547-573.

61 Kuipers E, Yesufu-Udechuku A, Taylor C, Kendall T: Management of psychosis and schizophrenia in adults: summary of updated NICE guidance. BMJ 2014;348:g1173.

62 Schlimme JE, Schwartz MA: In recovery from schizophrenia: regaining social cover: a phenomenological investigation. Psychopathology 2012;46:102-110.

63 Vassiliou A: The Intersubjective Arena of the Psychotherapy for Psychosis: A Phenomenological Account of Therapists' Experiences. London, Middlesex University London, 2016.

64 Ghaemi SN: No one is psychotic in my presence. Philos Psychiatr Psychol 2008;15:315319. 